\title{
Dandelion Extracts Protect Human Skin Fibroblasts from UVB Damage and Cellular Senescence
}

\author{
Yafan Yang' and Shuangshuang $\mathrm{Li}^{2}$ \\ ${ }^{1}$ Sir Winston Churchill Collegiate and Vocational Institute, Thunder Bay, ON, Canada P7C 1V5 \\ ${ }^{2}$ Cardiovascular and Metabolic Research Unit, Lakehead University, Thunder Bay, ON, Canada P7A 7T1 \\ Correspondence should be addressed to Shuangshuang Li; shu-li66@hotmail.com
}

Received 2 December 2014; Accepted 17 February 2015

Academic Editor: Felipe Simon

Copyright (c) 2015 Y. Yang and S. Li. This is an open access article distributed under the Creative Commons Attribution License, which permits unrestricted use, distribution, and reproduction in any medium, provided the original work is properly cited.

\begin{abstract}
Ultraviolet (UV) irradiation causes damage in skin by generating excessive reactive oxygen species (ROS) and induction of matrix metalloproteinases (MMPs), leading to skin photoageing. Dandelion extracts have long been used for traditional Chinese medicine and native American medicine to treat cancers, hepatitis, and digestive diseases; however, less is known on the effects of dandelion extracts in skin photoageing. Here we found that dandelion leaf and flower extracts significantly protect UVB irradiation-inhibited cell viability when added before UVB irradiation or promptly after irradiation. Dandelion leaf and flower extracts inhibited UVB irradiation-stimulated MMP activity and ROS generation. Dandelion root extracts showed less action on protecting HDFs from UVB irradiation-induced MMP activity, ROS generation, and cell death. Furthermore, dandelion leaf and flower but not root extracts stimulated glutathione generation and glutathione reductase mRNA expression in the presence or absence of UVB irradiation. We also found that dandelion leaf and flower extracts help absorb UVB irradiation. In addition, dandelion extracts significantly protected HDFs from $\mathrm{H}_{2} \mathrm{O}_{2}$-induced cellular senescence. In conclusion, dandelion extracts especially leaf and flower extracts are potent protective agents against UVB damage and $\mathrm{H}_{2} \mathrm{O}_{2}$-induced cellular senescence in HDFs by suppressing ROS generation and MMP activities and helping UVB absorption.
\end{abstract}

\section{Introduction}

When skin is aged, skin is more transparent, loose, and fragile. One of the most damaging actions on skin is from solar radiation, especially from its ultraviolet (UV) component, leading to both clinical and histologic damage on human skin $[1,2]$. UV irradiation causes distinct alterations of the connective tissues by generating excessive reactive oxygen species (ROS) and induction of matrix metalloproteinases (MMPs). MMPs-mediated degradation of the collagenous extracellular matrix (ECM) accounts for most of the connective tissue damage that occurs in photodamaged skin $[3,4]$. Dermal fibroblasts are responsible for generating ECM and allowing the skin to recover from injury [5].

UV irradiation consists of three components, UVA, UVB, and UVC. Whereas UVA and UVB reach the earth in sufficient amounts to damage the skin, UVC is almost completely absorbed by the ozone layer $[2,6]$. UVB is particularly damaging, as it penetrates the epidermis and the upper part of the dermis, where it damages fibroblast cells and leads to sunburn, photoageing, and skin cancer $[7,8]$. In Canada, sunlight is strong enough to cause skin cancer and premature ageing of the skin. People often use sunscreen to protect the skin from UV damaging from the sun, and sunscreen absorbs UV rays and prevents them from penetrating the skin. However some sunscreen ingredients, including oxybenzone, benzophenone, and octocrylene, have been shown to be potentially skin carcinogenic or penetrate into our body and have other health risks [9]. It is necessary to find effective, safer, and environmentally friendly nature products for antiageing and UV protection.

Taraxacum officinale, commonly known as dandelion, is widely distributed in the warmer temperate zone of the Northern Hemisphere [10]. Dandelion extracts have been used for centuries for traditional Chinese medicine and native American medicine to treat cancers, hepatitis, and digestive diseases [11-14]. Dandelion extracts are shown to have antiinflammatory, antioxidant, and anticarcinogenic activities; 
however, there are few scientific studies to investigate the effects of dandelion extracts in the treatment of skin diseases, especially photoageing $[10,15]$.

The purpose of this study was to determine whether dandelion leaf, flower, or root extracts can protect human dermal fibroblasts (HDFs) from UVB damage and cellular senescence and the underlying mechanisms. We found that dandelion leaf and flower extracts but not root extracts are potent protective agent against UVB damage and $\mathrm{H}_{2} \mathrm{O}_{2}$ induced cellular senescence in HDFs by suppressing ROS generation and MMP activities.

\section{Materials and Methods}

2.1. Preparation of Dandelion Extract. Dandelions were collected at flowering stage in June-July 2013 from the house yards in Thunder Bay (latitude $48^{\circ} 22^{\prime} 56^{\prime \prime} \mathrm{N}$; longitude $\left.89^{\circ} 14^{\prime} 46^{\prime \prime} \mathrm{W}\right)$, Ontario, Canada. Leaf, flower, and root were separated, cleaned, and air-dried before extraction through 4 hours of boiling in distilled water $[13,16]$. The water extracts were filtered through grade 1 Whatman filter paper under vacuum, concentrated, and then dissolved in distilled water following filtration through a $0.2 \mu \mathrm{m}$ filter to avoid cell contamination, and $300 \mathrm{mg} / \mathrm{mL}$ stock aqueous extract was prepared and stored at $4^{\circ} \mathrm{C}$ for experimental use. The identity of plant was confirmed by Dr. Wei Cao (Lakehead University), and the herbarium specimens were deposited in Cardiovascular and Metabolic Research Unit, Lakehead University for future reference.

2.2. Cell Culture. HDFs were obtained from American Type Culture Collection (Manassas, VA) and cultured with Dulbecco's modified Eagle's medium supplemented with $10 \%$ fetal bovine serum, $100 \mathrm{U} / \mathrm{mL}$ penicillin, and $100 \mu \mathrm{g} / \mathrm{mL}$ streptomycin and grown in a $\mathrm{CO}_{2}$ incubator at $37^{\circ} \mathrm{C}$ in $5 \%$ $\mathrm{CO}_{2}[17,18]$. The experiments were performed when the cells reached $70-80 \%$ confluence between passages 4 and 8 . In all studies, cells were incubated in the serum-free medium for $12 \mathrm{~h}$, and then $10 \%$ serum added together with different treatments. The media were changed every three days.

2.3. Cellular Viability Assays. Cell viabilities were measured based on conversion of yellow tetrazolium salt 3-(4,5-dimethylthiazol-2-yl)-2,5-diphenyltetrazolium bromide (MTT) to dark blue formazan by viable cells $[19,20]$. Briefly, cells at equal number were plated onto each well of 96-well plates for $24 \mathrm{~h}$. After treatment, $100 \mu \mathrm{L}$ medium containing $5 \mathrm{mg} / \mathrm{mL}$ MTT was added to each well, and the cells were then cultured at $37^{\circ} \mathrm{C}$ for $4 \mathrm{~h}$. The medium was then discarded and the crystals were dissolved in dimethyl sulfoxide and absorbance of formazan products at $570 \mathrm{~nm}$ was measured in a Multiskan spectrum microplate spectrophotometer (Thermo Labsystems, Franklin, MA). The cells incubated with control medium were considered $100 \%$ viable.

2.4. UVB Irradiation. HDFs were rinsed with phosphate buffered saline (PBS) and irradiated using a UVB lamp (UVB-18, Claremont, CA) with a wavelength range of 280$315 \mathrm{~nm}$ [3, 21]. UVB was administered for 60 seconds $\left(200 \mathrm{~mJ} / \mathrm{cm}^{2}\right)$ and the cells were cultured for another 24 hours following detection of cell viability. Dandelion extracts were added 30 minutes before or immediately after UVB radiation. The control cells were untreated with UVB irradiation.

2.5. Measurement of ROS and Glutathione (GSH) Contents. $2^{\prime}, 7^{\prime}$-Dichlorodihydrofluorescein diacetate ( $\left.\mathrm{H}_{2} \mathrm{DCFDA}\right)$ (Invitrogen, Carlsbad, CA) was used to detect ROS [13, 22]. After treatments, HDFs cultured in $35 \mathrm{~mm}$ plates were washed with PBS once and then incubated with $1 \mu \mathrm{g} / \mathrm{mL}$ $\mathrm{H}_{2}$ DCFDA in medium for 30 minutes at $37^{\circ} \mathrm{C}$. Then the cells were rinsed twice in PBS, and the fluorescence signals were detected using a fluorescent microscope. ImageJ software was used to quantify fluorescent intensity. Total GSH contents were measured using a commercial GSH assay kit (Cayman Chemical, Ann Arbor, MI), as previously described.

2.6. UV Absorption. UV absorption ability of dandelion extracts in medium $(300 \mu \mathrm{g} / \mathrm{mL})$ under $280,290,300$, and $310 \mathrm{~nm}$ was measured with a UV-visible spectrophotometer [23].

2.7. Cell Staining for MMPs. After treatments, HDFs cultured in $35 \mathrm{~mm}$ plates were incubated with $1 \mu \mathrm{g} / \mathrm{mL}$ DQ gelatin (Invitrogen) for 30 minutes to analyze MMP activity under a fluorescent microscope. ImageJ software was used to quantify fluorescent intensity. DQ gelatin is a fluorogenic substrate used to detect MMP activity [4, 20]. Upon digestion, its green fluorescence is revealed to be used to measure MMP activity.

2.8. Determination of $m R N A$ Level. Total RNA of HDFs was isolated using TriReagent (Invitrogen) [24]. First strand cDNA was prepared by reverse transcription using $\mathrm{M}$ MuLV reverse transcriptase and random hexamer primers according to manufacturer's protocol (New England Biolabs, Pickering, ON). Real-time PCR was performed in an iCycler $\mathrm{iQ}^{5}$ apparatus (Bio-Rad, Mississauga, ON) associated with the iCycler optical system software (version 3.1) using SYBR Green PCR Master Mix, as described previously. The primers of glutathione reductase (GR) were 5'-AGGGCCGCCGTGGTGGAGAGC-3' (forward, position 265-285) and $5^{\prime}$-ATGGGACTTGGTGAGATTGTTTTG-3' (reverse, position 475-498). These primers produced a product of $234 \mathrm{bp}$. The primers of $\beta$-actin were purchased from Ambion (Streetsville, ON), which produce a product of $295 \mathrm{bp}$. A standard curve was constructed using a series of dilution of total RNA (Ambion) transcribed to cDNA using the same protocol outlined above to confirm the same amplifying efficiency in the PCR. A standard melting curve analysis was performed using the following thermal cycling profile: $95^{\circ} \mathrm{C}$ for $10 \mathrm{~s}, 55^{\circ} \mathrm{C}$ for $15 \mathrm{~s}$, and ramping to $95^{\circ} \mathrm{C}$ at $1^{\circ}$ increments to confirm the absence of primer dimers. Relative mRNA quantification was calculated by using the arithmetic formula $2^{-\Delta \Delta C T}$, where $\Delta \mathrm{CT}$ is the difference between the threshold cycle of a given target cDNA and an endogenous reference $\beta$-actin cDNA.

2.9. Cell Ageing. Cell ageing was evaluated with senescenceassociated $\beta$-galactosidase (SA- $\beta$-gal) staining $[18,24]$. HDFs 


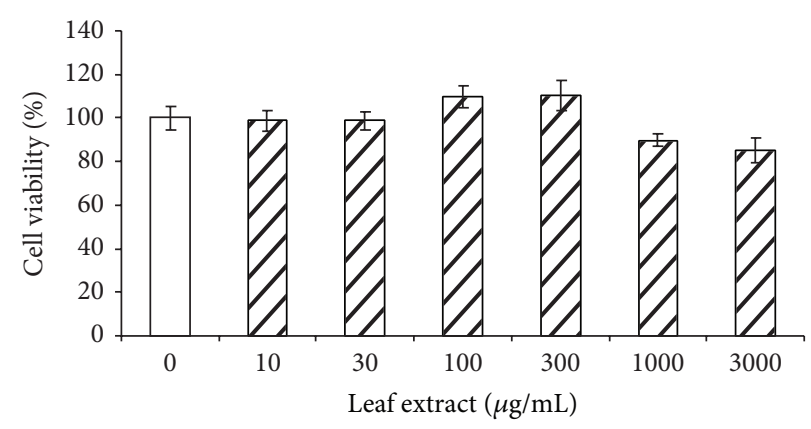

(a)

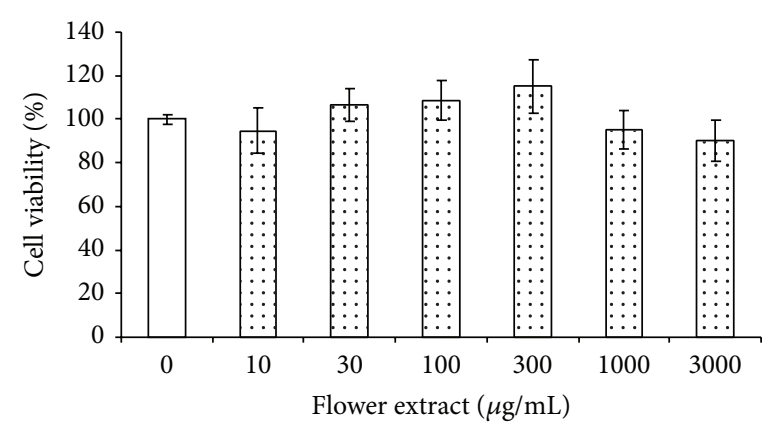

(b)

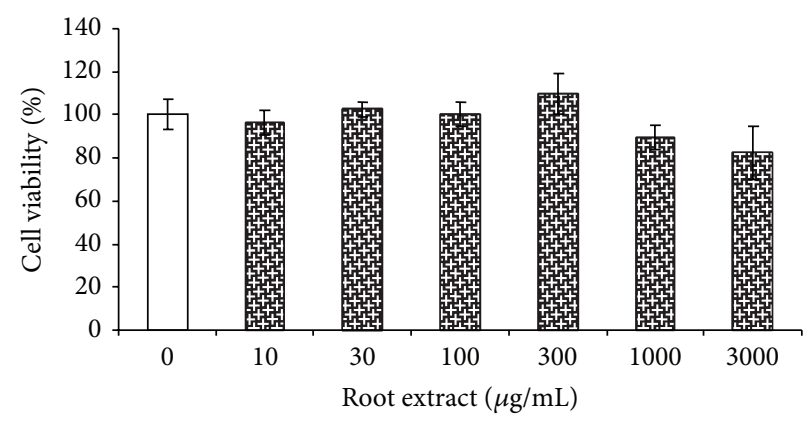

(c)

FIGURE 1: Dandelion extracts have no effect on HDFs cell viability. HDFs were treated with the extracts of dandelion leaf (a), flower (b), and root (c) at $10-3000 \mu \mathrm{g} / \mathrm{mL}$ for 24 hours, and cell viability was then measured with MTT method. $n=4$.

cultured in $35 \mathrm{~mm}$ plates were treated with $\mathrm{H}_{2} \mathrm{O}_{2}(100 \mu \mathrm{M})$ with or without dandelion extracts $(300 \mu \mathrm{g} / \mathrm{mL})$ for 72 hours. After that, the cells were fixed and stained with X-gal at $\mathrm{pH}$ 6.0 overnight. Nuclei were stained with $4^{\prime}, 6$-diamidino-2phenylindole (DAPI, $1 \mu \mathrm{g} / \mathrm{mL}$ ) for cell counting. The percentage of ageing cells was calculated as the ratio of blue-stained cells to total cells counted. More than 600 cells were counted from each group.

2.10. Materials and Data Analysis. All chemicals were purchased from Sigma (St. Louis, MO) unless stated otherwise. Student's $t$-test in Microsoft excel was used to analyze data between control and treatment group, and the data were presented as mean \pm standard error of the mean. Experiments were repeated a minimum of 3 times. Statistical significance was set at $P<0.05$.

\section{Results}

3.1. Dandelion Leaf and Extracts Protect UVB IrradiationInduced Cell Death. The dandelion extracts were prepared from dandelion leaves, flowers, and root, separately, and the extract rate was $10.6 \%, 11.2 \%$, and $12.7 \%$, respectively. Dandelion extracts alone at $10-3000 \mu \mathrm{g} / \mathrm{mL}$ had no effect on HDFs cell viability (Figure 1). When dandelion extracts (30, 100 , and $300 \mu \mathrm{g} / \mathrm{mL}$ ) were added into HDFs for 30 minutes before UVB irradiation (Figures 2(a) and 2(b)) or when added promptly after irradiation (Figures $2(\mathrm{a})$ and 2(c)), leaf and flower extracts significantly protected UVB irradiationinhibited cell viability. Dandelion root extracts had less effect on UVB-induced cell death when added into HDFs 30 minutes before UVB irradiation. Although supplement of dandelion root extract at $300 \mu \mathrm{g} / \mathrm{mL}$ immediately after irradiation significantly protected HDFs from UVB-induced cell damage, it was quite inefficient compared with the same dose of leaf and flower extracts (Figure 2(b)).

3.2. Dandelion Leaf and Flower Extracts Inhibit UVB Irradiation-Stimulated MMP Activity and Oxidative Stress. UVB irradiation strengthened the fluorescent intensity of DQ gelatin (Figure 3 ) and $\mathrm{H}_{2}$-DCFDA (Figure 4 ), reflecting the higher activities of MMPs and higher level of ROS, which leads to degradation of ECM and induction of cell death $[4,13]$. Dandelion leaf and flower extracts $(300 \mu \mathrm{g} / \mathrm{mL})$ significantly reversed UVB irradiation-induced MMP activity and ROS generation when added either before or after UVB irradiation (Figures 3 and 4). Dandelion root extracts showed less action on protecting HDFs from UVB irradiationinduced MMP activity and ROS generation.

\subsection{Dandelion Leaf and Flower Extracts Stimulate GSH} Generation and GR mRNA Expression. GSH is master antioxidant in our body [24]. We observed that GSH level is significantly lower in UVB-irradiated HDFs $(0.075 \mathrm{mg} / \mathrm{mg}$ protein), which is completely reversed by dandelion leaf and flower extracts but not dandelion root extracts. Dandelion leaf and flower extracts alone also significantly increased GSH level $(0.45 \mathrm{mg} / \mathrm{mg}$ protein and $0.46 \mathrm{mg} / \mathrm{mg}$ protein, resp.) compared with the control cells $(0.3 \mathrm{mg} / \mathrm{mg}$ protein) (Figure 5(a)). GR reduces glutathione disulfide to form GSH 

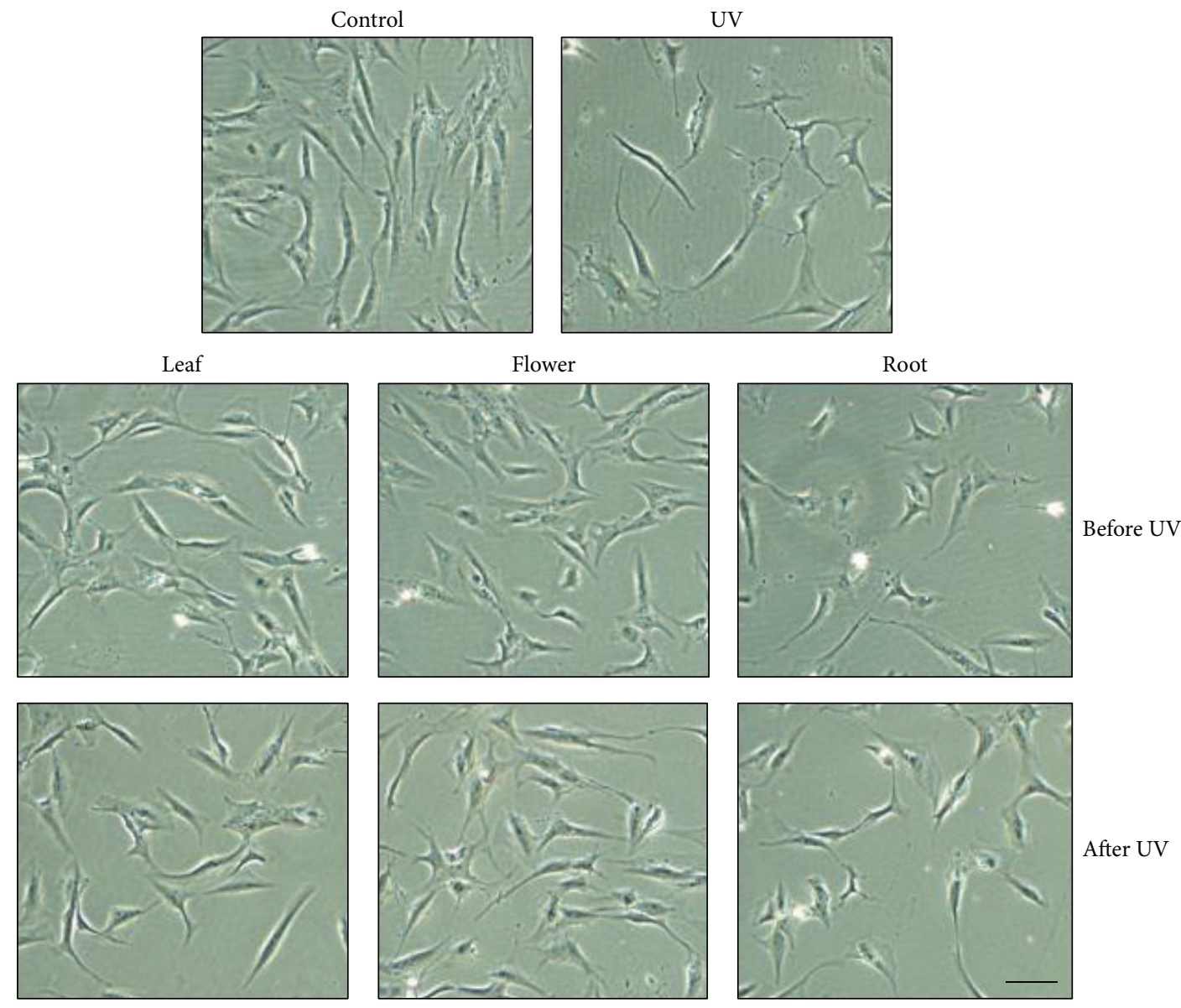

(a)

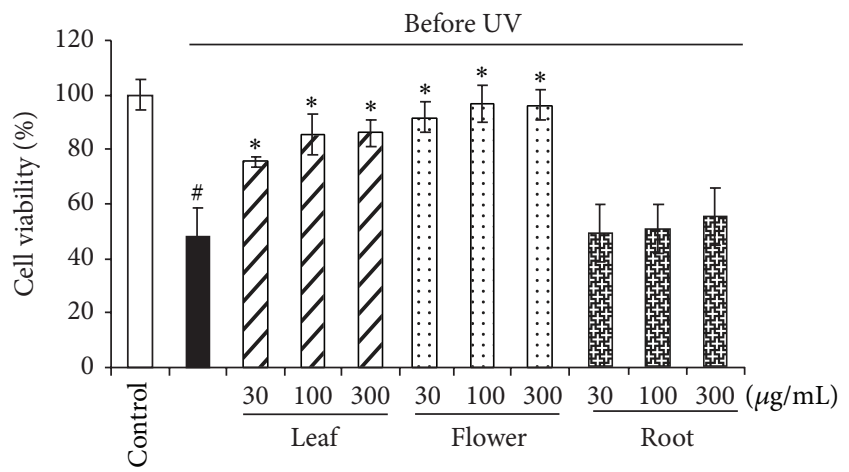

(b)

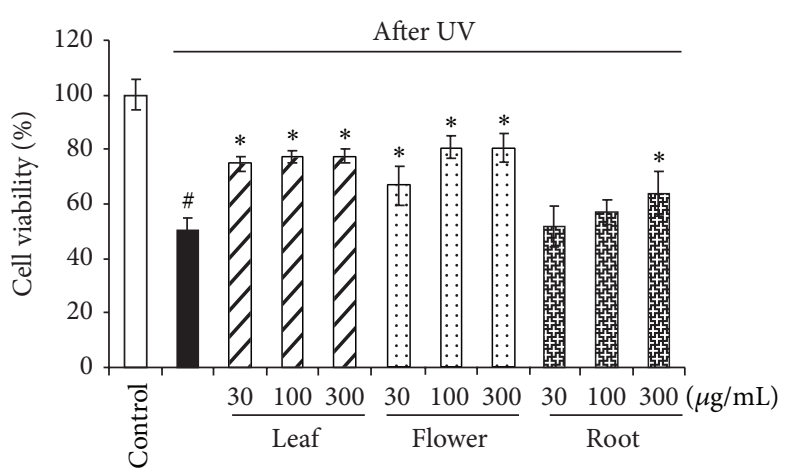

(c)

FIGURE 2: Dandelion leaf and flower extracts protect HDFs from UVB irradiation-induced damage. Dandelion extracts at the indicated concentrations were added 30 minutes before UVB $\left(200 \mathrm{~mJ} / \mathrm{cm}^{2}\right)$ (b) or promptly after UVB radiation (c). Cell viability was measured by MTT 24 hours after culture. ${ }^{\#} P<0.05$ versus control; ${ }^{*} P<0.05$ versus UVB only. Images in (a) were taken under microscope showing UVB irradiation damages cells, but dandelion leaf and flower extracts $(300 \mu \mathrm{g} / \mathrm{mL})$ protected the cells added from either before or after UVB radiation. Under UVB irradiation, the cells became smaller and less in number. Scale bar: $20 \mu \mathrm{m} . n=3$.

and is an important GSH-maintaining gene [25]. The mRNA expression of GR was decreased by $62.0 \%$ in UVB-irradiated HDFs in comparison with the control cells (Figure 5(b)). Consistent with the GSH data, incubation of HDFs with dandelion leaf and flower extracts significantly induced GR mRNA expression by $29.1 \%$ and $37.2 \%$ compared with the control HDFs even in the presence of UVB irradiation. In addition, dandelion leaf and flower extracts alone stimulated GR mRNA expression by $89.4 \%$ and $116.2 \%$, respectively. Dandelion root extract had no effect on GR mRNA expression in the presence or absence of UVB irradiation (Figure 5(b)). 


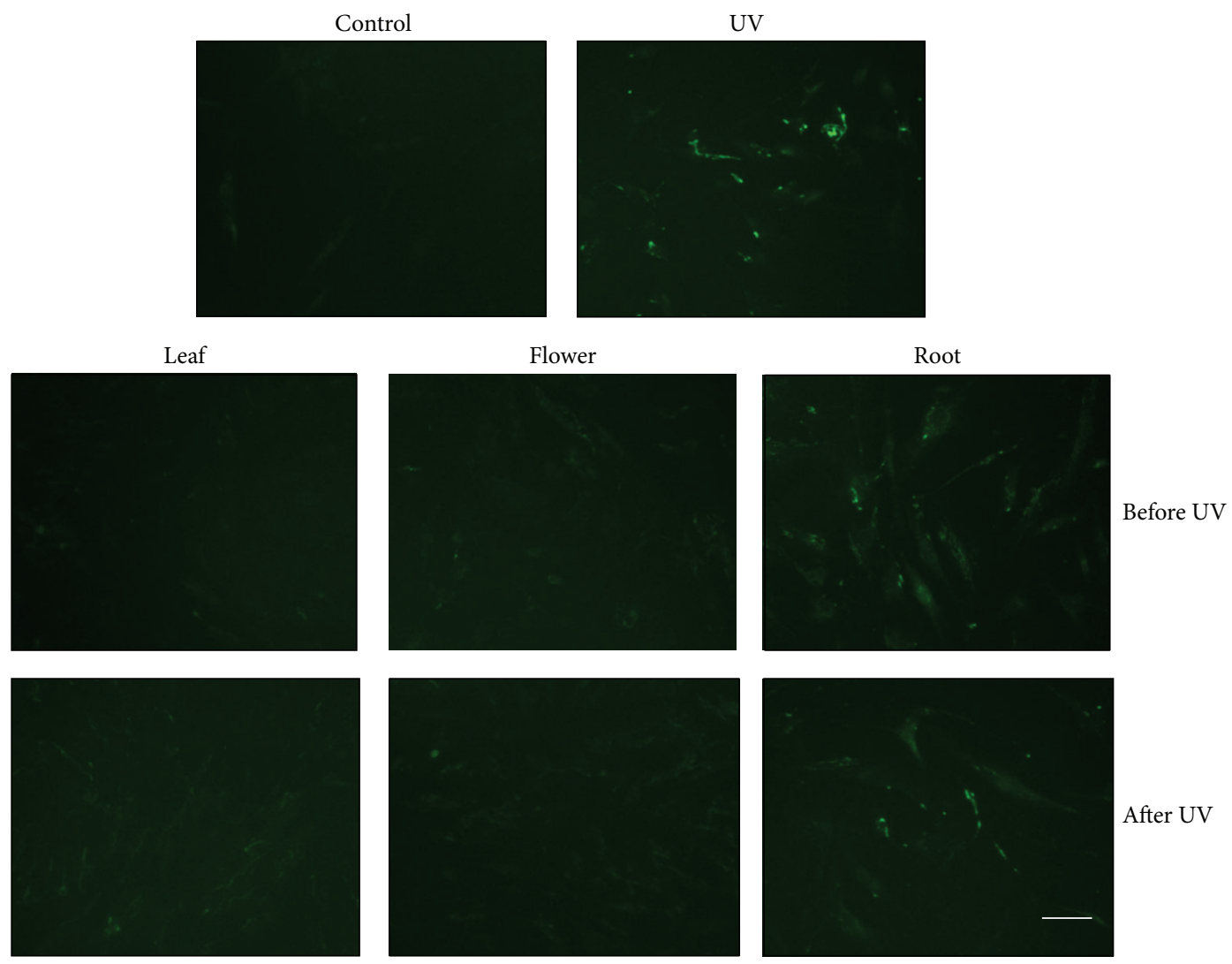

(a)

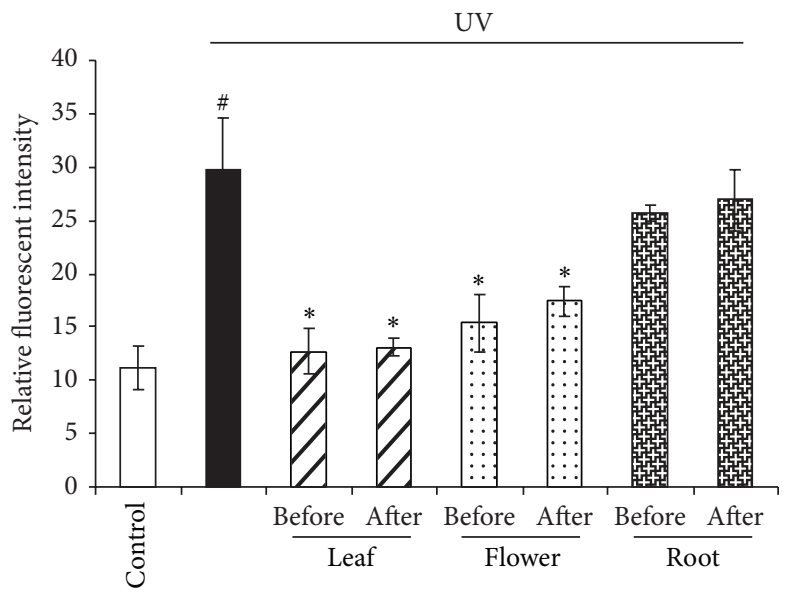

(b)

FIGURE 3: Dandelion leaf and flower extracts inhibit UVB irradiation-stimulated MMP activity. UVB irradiation strengthened the fluorescent intensity of DQ gelatin, reflecting higher MMP activity; however, dandelion leaf and flower extracts (300 $\mu \mathrm{g} / \mathrm{mL})$ significantly decreased MMP activity when added both before and after UVB irradiation. Scale bar: $20 \mu \mathrm{m}$. (b) was the statistical analysis from (a) by imageJ software. ${ }^{\#} P<0.05$ versus control; ${ }^{*} P<0.05$ versus UVB only. $n=3$. Scale bar: $20 \mu \mathrm{m}$.

3.4. Dandelion Leaf and Flower Extracts Help UV Absorption. As shown in Figure 6, dandelion extracts could help absorb UV irradiation. At the wavelengths of $300 \mathrm{~nm}$ and $310 \mathrm{~nm}$, flower and leaf extracts had the highest UV absorption capacity. At $290 \mathrm{~nm}$, dandelion root extracts displayed higher UV absorption ability compared with dandelion leaf extract but significantly lower than dandelion flower extract. These data suggest the protective role of dandelion extracts against UV irradiation is partially through UV absorption.

3.5. Dandelion Leaf and Flower Extracts Protect $\mathrm{H}_{2} \mathrm{O}_{2}$ Induced Cell Ageing. Oxidative stress has been considered one of crucial factors associated with cellular senescence. To 


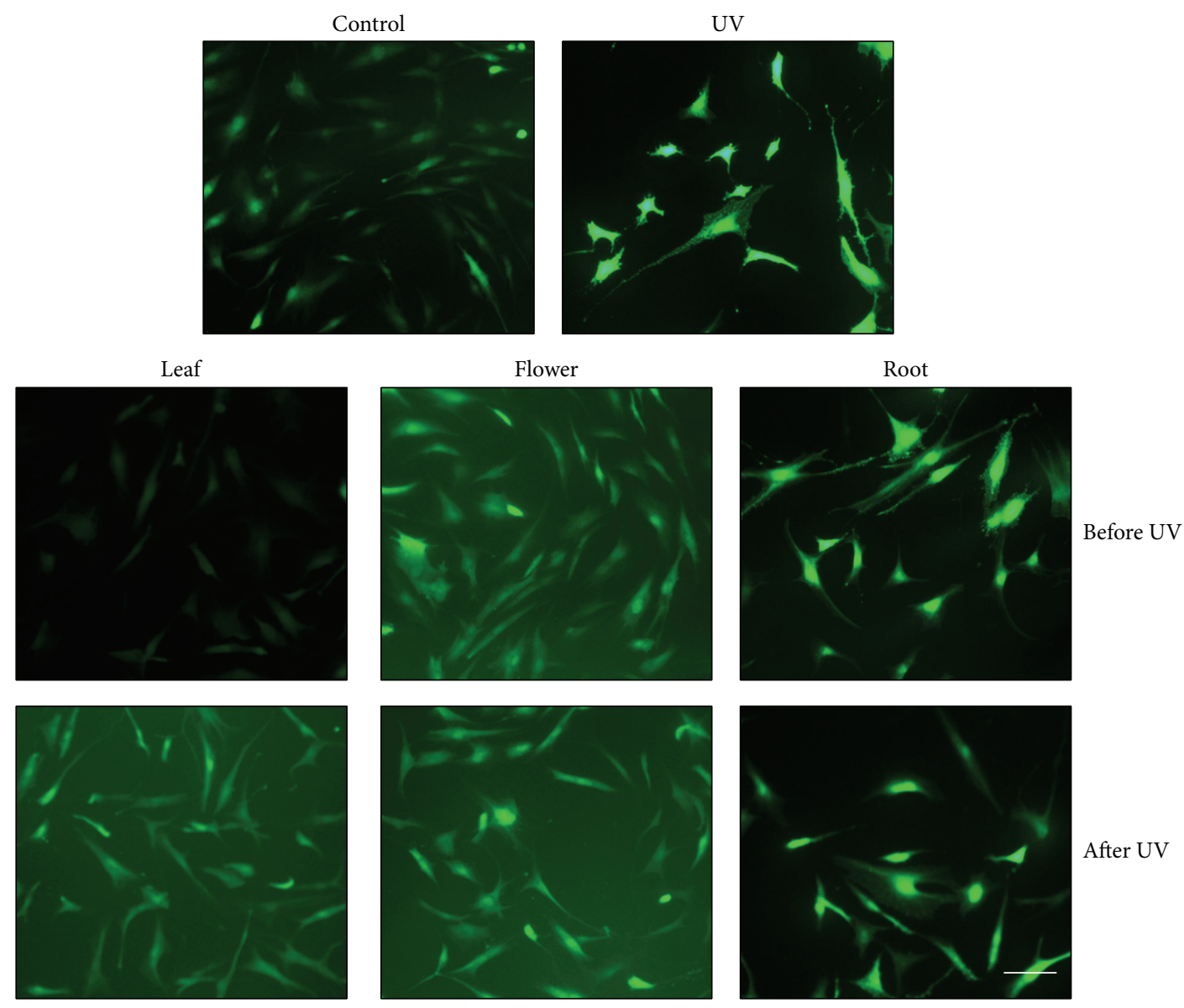

(a)

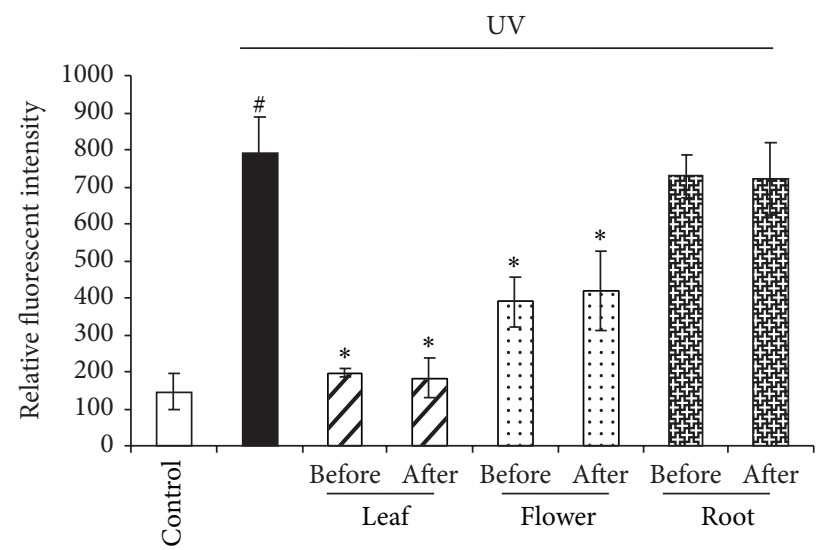

(b)

FIGURE 4: Dandelion leaf and flower extracts inhibit UVB irradiation-induced ROS production. UVB irradiation caused significant increases in the fluorescent intensity of $\mathrm{H}_{2}$-DCFDA, reflecting the higher level of ROS; however, dandelion leaf and flower extracts $(300 \mu \mathrm{g} / \mathrm{mL})$ significantly decreased UVB irradiation-induced ROS generation when added both before and after UVB irradiation. (b) was the statistical analysis from (a) by imageJ software. ${ }^{\#} P<0.05$ versus control; ${ }^{*} P<0.05$ versus UVB only. $n=3$. Scale bar: $20 \mu \mathrm{m}$.

study the protective roles of dandelion extracts on oxidative stress-induced premature senescence, we treated HDFs with $\mathrm{H}_{2} \mathrm{O}_{2}$, one main source of oxidative stress. HDFs became enlarged and flattened with a decreased nucleus-tocytoplasm ratio after $\mathrm{H}_{2} \mathrm{O}_{2}(100 \mu \mathrm{M})$ treatment for 72 hours (Figure 7(a)), showing the typical characteristics of senescent cells $[18,21]$. The cells were then stained for SA- $\beta$-gal, and the data showed that $78.6 \%$ of cells in the $\mathrm{H}_{2} \mathrm{O}_{2}$-treated group become aged (stained with blue); however, dandelion leaf, flower, and root extracts $(300 \mu \mathrm{g} / \mathrm{mL})$ significantly protect $\mathrm{H}_{2} \mathrm{O}_{2}$-induced cell ageing by $61.8 \%, 73.3 \%$, and $40.0 \%$, respectively (Figure $7(\mathrm{~b})$ ). 


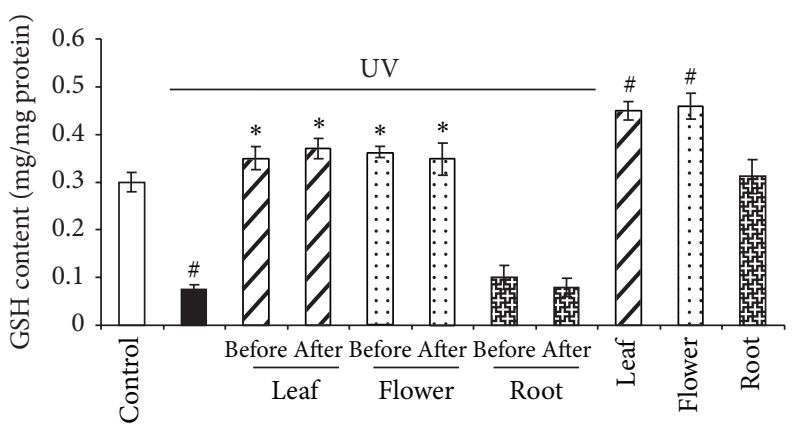

(a)

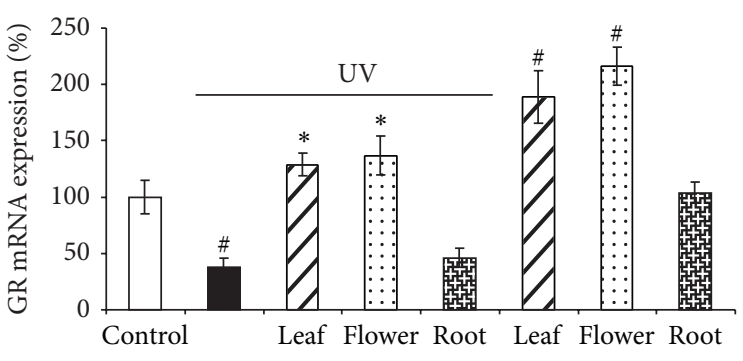

(b)

FIGURE 5: Dandelion leaf and flower extracts stimulate GSH generation and the expression of GR. (a) Dandelion leaf and flower extracts protected UVB irradiation-decreased GSH level. Dandelion extracts $(300 \mu \mathrm{g} / \mathrm{mL})$ were added 30 minutes before UVB or promptly after UVB radiation, and GSH was measured after additional 24 -hour culture. ${ }^{\#} P<0.05$ versus control; ${ }^{*} P<0.05$ versus UVB only. $n=3$. (b) Dandelion leaf and flower extracts stimulated GR mRNA expression. Dandelion extracts $(300 \mu \mathrm{g} / \mathrm{mL})$ were added 30 minutes before UVB, and GR mRNA was measured after additional 24 -hour culture with real-time PCR. ${ }^{\#} P<0.05$ versus control; ${ }^{*} P<0.05$ versus UVB only. $n=3$.

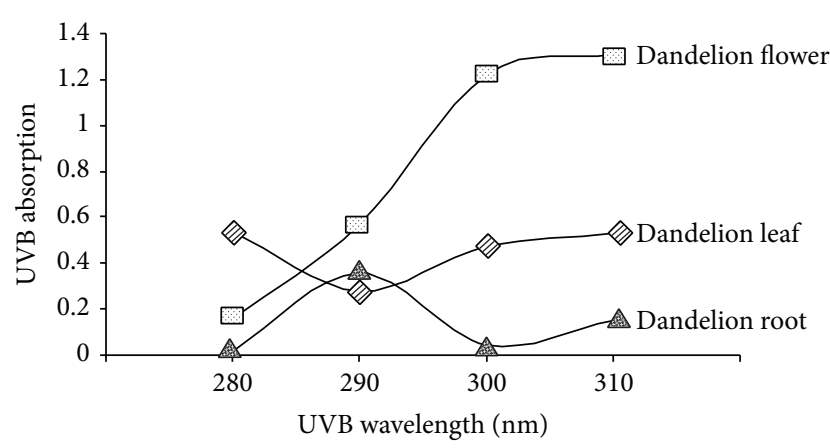

FIGURE 6: Dandelion extracts help absorb UV irradiation. At wavelengths of $300 \mathrm{~nm}$ and $310 \mathrm{~nm}$, flower and leaf extracts had the highest UV absorption capacity. UV absorption of dandelion extracts $(300 \mu \mathrm{g} / \mathrm{mL})$ was measured with a UV spectrometer at 280, 290, 300, and $310 \mathrm{~nm}$, respectively. $n=3$.

\section{Discussion}

In recent years, interest on the research of herb medicine has increased all over the world. Many herb extracts have shown therapeutic properties as reported elsewhere $[2,6$, $19,20,23]$. Dandelion is one of the most common and recognizable herbs and is found in almost every part of the world. Many studies have shown that dandelion extracts have a wide range of pharmacological activities, including anticarcinogenic, antioxidant, anti-inflammatory, and antiheart burn activities $[10,11,16]$; however, there are limited scientific studies investigating the antiageing and anti-UV activity of dandelion extracts and very little is known about the mechanisms of action.

Skin ageing is mainly attributed to extrinsic (photoageing) and intrinsic (chronological ageing) processes that are often manifested by increased wrinkles, loss of tensions and elasticity, and altered pigmentation, and so forth $[1,8]$. Dermal fibroblasts are within the dermis layer of skin and are responsible for generating connective tissues, including laminin and fibronectin which comprise the ECM [5].
In this study, we found that exposure of HDFs to UVB leads to reduced cell viability. Without dermal fibroblasts, the skin cannot properly recover from injury. Recognition of supplementing natural antioxidant components in skin care is growing important among dermatologists and other medical professionals. Sunscreens are considered to be the gold standard for protecting skin from UV damage. It is recently noted that sunscreen ingredients may become free radicals themselves when activated by UV radiation. In addition, sunscreen chemicals may be absorbed into the skin, causing harmful effect [9]. Here we demonstrated that supplement of dandelion leaf and flower extracts at as lower as $30 \mu \mathrm{g} / \mathrm{mL}$ rescued the cells from UVB-induced cell death, suggesting dandelion may be useful for preventing and treating skin photoageing. More importantly, dandelion extracts produce protective action when added at both before and after UVB irradiation, pointing to the convenient use of this new product. The dandelion extracts at the concentration as higher as $3 \mathrm{mg} / \mathrm{mL}$ did not affect cell growth, so dandelion leaf and flower water extracts would be a green choice for development of novel sunscreens.

It is well established that cutaneous exposure to UV irradiation causes higher activities of MMPs and excessive production of ROS $[4,8,26]$. Our studies further validated that UVB irradiation in HDFs induces significantly higher MMP activities and ROS level. Increased activation of MMPs causes the degradation or disorganization of skin connective tissues, which would lead to increased skin wrinkles and loss of skin tone [5]. Oxidative stress is one of the primary causes of skin ageing, and it is believed that oxidative stress is caused by an imbalance between the production of ROS and skin cell's ability to clean up the reactive intermediates [24]. This is really the case, and the present study found that UVB irradiation markedly decreased the content of GSH, a master antioxidant inside the cells. The reduced expression of GR, a GSH producing gene, would be attributed to the lower level of GSH by UVB irradiation [25]. With less GSH generation, the cells will have less ability to remove overproduced ROS. Excitedly, dandelion leaf and flower extracts attenuated 

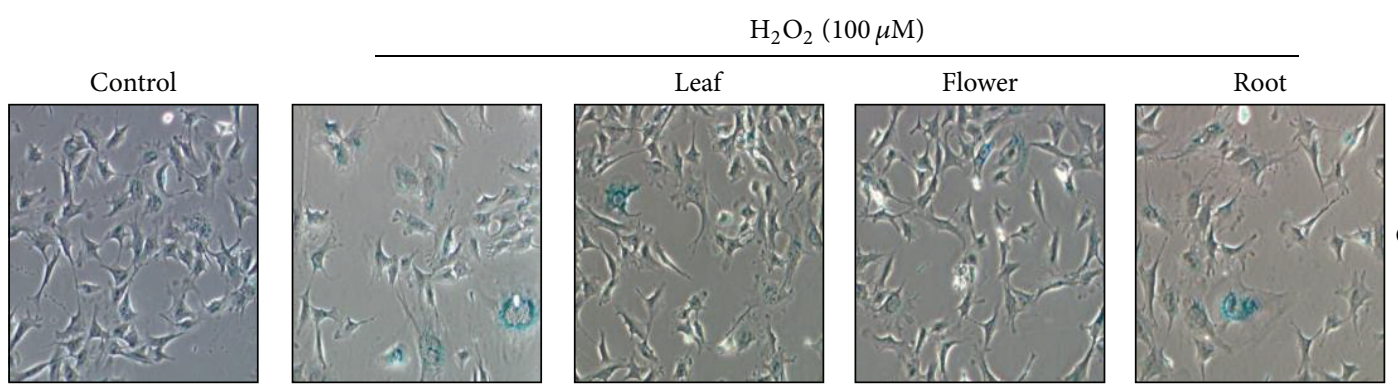

Cell senescence staining
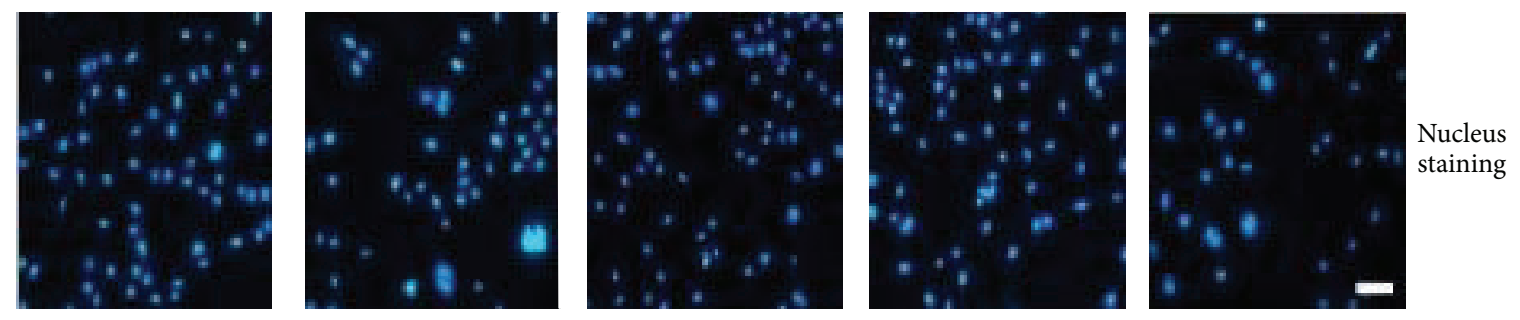

(a)

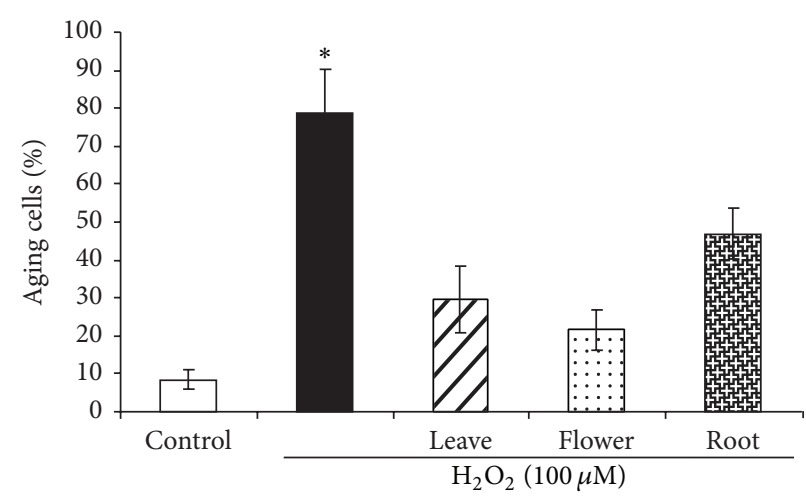

(b)

Figure 7: Dandelion leaf and flower extracts protect $\mathrm{H}_{2} \mathrm{O}_{2}$-induced cell ageing. (a) The images showed that $\mathrm{H}_{2} \mathrm{O}_{2}$ provokes cell ageing, which is protected by dandelion extracts. The ageing cells had higher gal activity and stained with blue color. HDFs were also incubated with DAPI for nucleus staining for cell counting. Scale bar: $20 \mu \mathrm{m}$. (b) was the statistical analysis from (a). HDFs were treated with $\mathrm{H}_{2} \mathrm{O}_{2}(100 \mu \mathrm{M})$ with or without dandelion extracts $(300 \mu \mathrm{g} / \mathrm{mL})$ for 72 hours. The percentage of aged cells was calculated from the number of blue-stained cells to total cells counted. ${ }^{*} P<0.05$ compared all other groups.

UVB-induced MMP activation and ROS generation, with leaf extracts having higher efficiency. Incubation of HDFs with either dandelion leaf or flower extracts alone significantly increased GR mRNA expression and GSH generation. Even in the presence of UVB irradiation, dandelion leaf and flower extracts maintained intracellular GSH level unchanged. All these data indicate that dandelion leaf and flower extracts can protect HDFs from UVB-induced cell death by increasing GSH generation, inhibiting MMP activities and ROS generation.

Ageing at the cellular level is known as cellular senescence $[18,24]$. Oxidative stress has been considered one of crucial factors associated with cellular senescence. Most of the senescent cells have flattened cell morphology, promiscuous gene expression, a proinflammatory secretory response, and positive SA- $\beta$-gal staining at $\mathrm{pH} 6.0$ [18]. Exposure of HDFs to lower doses of $\mathrm{H}_{2} \mathrm{O}_{2}(100 \mu \mathrm{M})$ for 72 hours induced premature senescence, as evidenced by enlarged and flattened cell morphology with a decreased nucleus-to-cytoplasm ratio, and most of the cells were stained blue for SA- $\beta$-gal, the typical characteristics of senescent cells. All these changes by $\mathrm{H}_{2} \mathrm{O}_{2}$ in $\mathrm{HDF}$ were significantly reversed by dandelion extracts. Dandelion extracts improve cellular ageing possibly by directly altering the expressions of senescence-related genes, such as p53, or indirectly lowering oxidative stress.

Unlike dandelion leaf and flower extracts, dandelion root extracts had less effect on UV protection. Compared to dandelion roots, dandelion leaves and flowers are characterized by higher polyphenol contents [10]. So it is highly possible that polyphenols but not other components contribute to the protective role of dandelion leaf and flower extracts against UV damage. Most of the components of dandelion leaf and flower extract have been isolated and identified, and some of the important components of the extract, including sesquiterpene lactones and phenylpropanoids, are believed to have anti-inflammatory, antioxidative, and anticancer properties. Whether these components are also playing the critical roles in protecting HDFs from UVB damage needs to be tested. 
Other components which have not been fully characterized also need to be explored.

In conclusion, dandelion water extracts are able to protect HDFs against UVB damage, before irradiation and also when added promptly after irradiation, via increased UV absorption and reduced MMP activity and oxidative stress. The extracts are also able to prevent oxidative stress-induced premature senescence; however, with both UV protection and antiageing, the root extracts have the smallest effect compared with leaf and flower extracts. These findings can lead to more effective, safer, and environmentally friendly antiageing and UV protection. Future studies, both preclinical and clinical, will be necessary to test the efficacy of dandelion extracts for photoageing.

$\begin{array}{ll}\text { Abbreviations } \\ \text { ECM: } & \text { Extracellular matrix } \\ \text { HDF: } & \text { Human dermal fibroblasts } \\ \text { GR: } & \text { Glutathione reductase } \\ \text { GSH: } & \text { Glutathione } \\ \text { MMP: } & \text { Matrix metalloproteinase } \\ \text { MTT: } & \text { 3-(4,5-Dimethylthiazol-2-yl)-2,5- } \\ & \text { diphenyltetrazolium bromide } \\ \text { PBS: } & \text { Phosphate buffered saline } \\ \text { ROS: } & \text { Reactive oxygen species } \\ \text { SA- } \beta \text {-gal: } & \text { Senescence-associated } \beta \text {-galactosidase } \\ \text { UV: } & \text { Ultraviolet. }\end{array}$

\section{Conflict of Interests}

The authors declare that there is no conflict of interests regarding the publication of this paper.

\section{Acknowledgments}

The authors would like to thank Drs. Yaoge Huang and Wei Cao in Lakehead University for suggestion and comments on this project as well as the identification of the plants, and they are also very grateful for the generous support and guidance from all the members in the Cardiovascular and Metabolic Research Unit, Lakehead University, Thunder Bay, Ontario.

\section{References}

[1] J. E. Sanches Silveira and D. M. Myaki Pedroso, "UV light and skin aging," Reviews on Environmental Health, vol. 29, no. 3, pp. 243-254, 2012.

[2] B. R. Zhou, H. B. Yin, Y. Xu et al., "Baicalin protects human skin fibroblasts from ultraviolet A radiation-induced oxidative damage and apoptosis," Free Radical Research, vol. 46, pp. 14581471, 2012.

[3] J. Y. Cherng, L. Y. Chen, and M. F. Shih, "Preventive effects of $\beta$ thujaplicin against UVB-induced MMP-1 and MMP-3 mRNA expressions in skin fibroblasts," American Journal of Chinese Medicine, vol. 40, no. 2, pp. 387-398, 2012.

[4] F. Liebel, S. Kaur, E. Ruvolo, N. Kollias, and M. D. Southall, "Irradiation of skin with visible light induces reactive oxygen species and matrix-degrading enzymes," Journal of Investigative Dermatology, vol. 132, no. 7, pp. 1901-1907, 2012.
[5] T. Quan, Z. Qin, Y. Xu et al., "Ultraviolet irradiation induces CYR61/CCN1, a mediator of collagen homeostasis, through activation of transcription factor AP-1 in human skin fibroblasts," Journal of Investigative Dermatology, vol. 130, no. 6, pp. 1697-1706, 2010.

[6] Y. P. Hwang, J. H. Choi, H. G. Kim et al., "Cultivated ginseng suppresses ultraviolet $\mathrm{B}$-induced collagenase activation via mitogen-activated protein kinases and nuclear factor $\kappa \mathrm{B} /$ activator protein-1-dependent signaling in human dermal fibroblasts," Nutrition Research, vol. 32, no. 6, pp. 428-438, 2012.

[7] M. Ichihashi and H. Ando, "The maximal cumulative solar UVB dose allowed to maintain healthy and young skin and prevent premature photoaging," Experimental Dermatology, vol. 23, pp. 43-46, 2014.

[8] B. Poljšak and R. Dahmane, "Free radicals and extrinsic skin aging," Dermatology Research and Practice, vol. 2012, Article ID 135206, 4 pages, 2012.

[9] G. Bens, "Sunscreens," Advances in Experimental Medicine and Biology, vol. 810, pp. 429-463, 2014.

[10] K. Schütz, R. Carle, and A. Schieber, "Taraxacum-a review on its phytochemical and pharmacological profile," Journal of Ethnopharmacology, vol. 107, no. 3, pp. 313-323, 2006.

[11] S. J. Chatterjee, P. Ovadje, M. Mousa, C. Hamm, and S. Pandey, "The efficacy of dandelion root extract in inducing apoptosis in drug-resistant human melanoma cells," Evidence-Based Complementary and Alternative Medicine, vol. 2011, Article ID 129045, 11 pages, 2011.

[12] M. Hfaiedh, D. Brahmi, and L. Zourgui, "Hepatoprotective effect of Taraxacum officinale leaf extract on sodium dichromate-induced liver injury in rats," Environmental Toxicology, 2014.

[13] C. M. Park, J. Y. Park, K. H. Noh, J. H. Shin, and Y. S. Song, "Taraxacum officinale Weber extracts inhibit LPS-induced oxidative stress and nitric oxide production via the NF- $\kappa \mathrm{B}$ modulation in RAW 264.7 cells," Journal of Ethnopharmacology, vol. 133, no. 2, pp. 834-842, 2011.

[14] B.-R. Lee, J.-H. Lee, and H.-J. An, "Effects of taraxacum officinale on fatigue and immunological parameters in mice," Molecules, vol. 17, no. 11, pp. 13253-13265, 2012.

[15] U.-K. Choi, O.-H. Lee, J. H. Yim et al., "Hypolipidemic and antioxidant effects of dandelion (Taraxacum officinale) root and leaf on cholesterol-fed rabbits," International Journal of Molecular Sciences, vol. 11, no. 1, pp. 67-78, 2010.

[16] P. Ovadje, S. Chatterjee, C. Griffin, C. Tran, C. Hamm, and S. Pandey, "Selective induction of apoptosis through activation of caspase-8 in human leukemia cells (Jurkat) by dandelion root extract," Journal of Ethnopharmacology, vol. 133, no. 1, pp. 8691, 2011.

[17] K. Phetdee, R. Rakchai, K. Rattanamanee, T. Teaktong, and J. Viyoch, "Preventive effects of tamarind seed coat extract on UVA-induced alterations in human skin fibroblasts," Journal of Cosmetic Science, vol. 65, no. 1, pp. 11-24, 2014.

[18] X. Shen, Y. Du, W. Shen, B. Xue, and Y. Zhao, "Adipose-derived stem cells promote human dermal fibroblast function and increase senescence-associated $\beta$-galactosidase mRNA expression through paracrine effects," Molecular Medicine Reports, vol. 10, no. 6, pp. 3068-3072, 2014.

[19] A. Martínez, E. Conde, A. Moure, H. Domnguez, and R. J. Estévez, "Protective effect against oxygen reactive species and skin fibroblast stimulation of Couroupita guianensis leaf extracts," Natural Product Research, vol. 26, no. 4, pp. 314-322, 2012. 
[20] B.-M. Hwang, E.-M. Noh, J.-S. Kim et al., "Curcumin inhibits UVB-induced matrix metalloproteinase-1/3 expression by suppressing the MAPK-p38/JNK pathways in human dermal fibroblasts," Experimental Dermatology, vol. 22, no. 5, pp. 371374, 2013.

[21] E. Hwang, S. Y. Park, H. J. Lee et al., "Vigna angularis water extracts protect against ultraviolet b-exposed skin aging in vitro and in vivo," Journal of Medicinal Food, vol. 17, no. 12, pp. 13391349, 2014.

[22] M. Majeed, B. Bhat, S. Anand, A. Sivakumar, P. Paliwal, and K. G. Geetha, "Inhibition of UV-induced ROS and collagen damage by Phyllanthus emblica extract in normal human dermal fibroblasts," Journal of Cosmetic Science, vol. 62, no. 1, pp. 49-56, 2011.

[23] A. R. Silva, C. Seidl, A. S. Furusho, M. M. S. Boeno, G. C. Dieamant, and A. M. Weffort-Santos, "In vitro evaluation of the efficacy of commercial green tea extracts in UV protection," International Journal of Cosmetic Science, vol. 35, no. 1, pp. 6977, 2013.

[24] G. Yang, K. Zhao, Y. Ju et al., "Hydrogen sulfide protects against cellular senescence via s-sulfhydration of keap1 and activation of Nrf2," Antioxidants and Redox Signaling, vol. 18, no. 15, pp. 1906-1919, 2013.

[25] H.-S. Wong, J.-H. Chen, P.-K. Leong, H.-Y. Leung, W.-M. Chan, and K.-M. Ko, “ $\beta$-sitosterol protects against carbon tetrachloride hepatotoxicity but not gentamicin nephrotoxicity in rats via the induction of mitochondrial glutathione redox cycling," Molecules, vol. 19, no. 11, pp. 17649-17662, 2014.

[26] D. M. Palmer and J. S. Kitchin, "Oxidative damage, skin aging, antioxidants and a novel antioxidant rating system," Journal of Drugs in Dermatology, vol. 9, no. 1, pp. 11-15, 2010. 


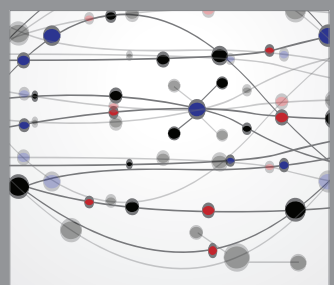

The Scientific World Journal
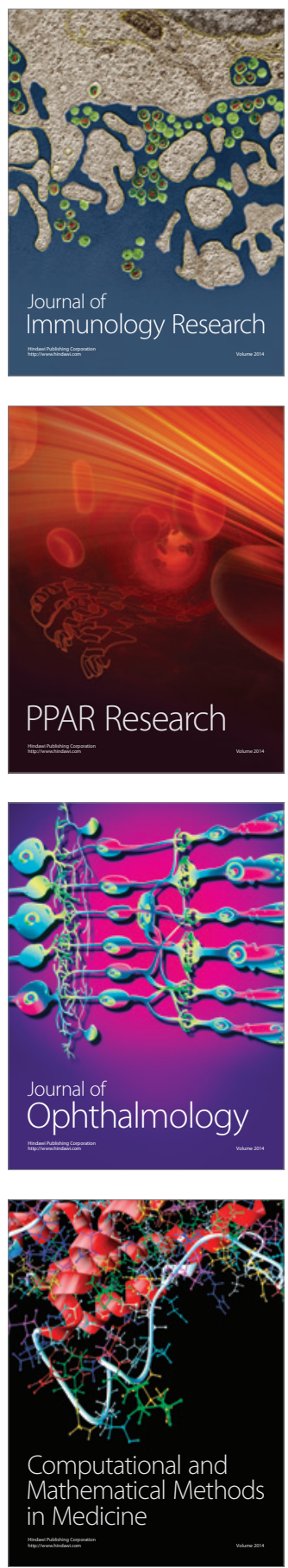

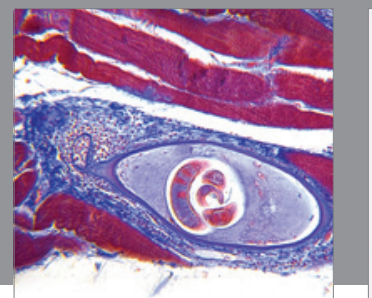

Gastroenterology

Research and Practice
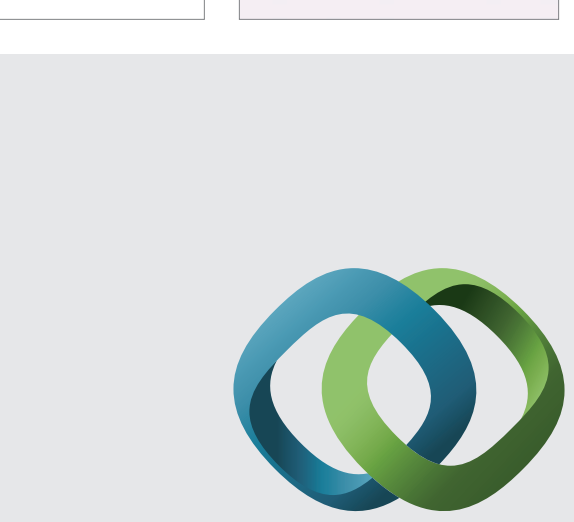

\section{Hindawi}

Submit your manuscripts at

http://www.hindawi.com
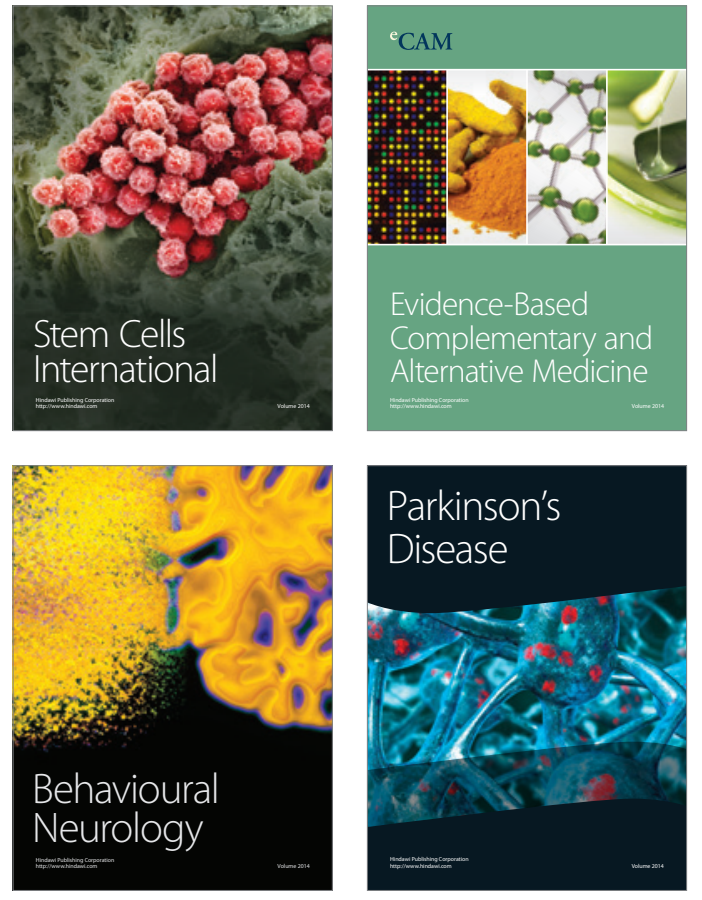
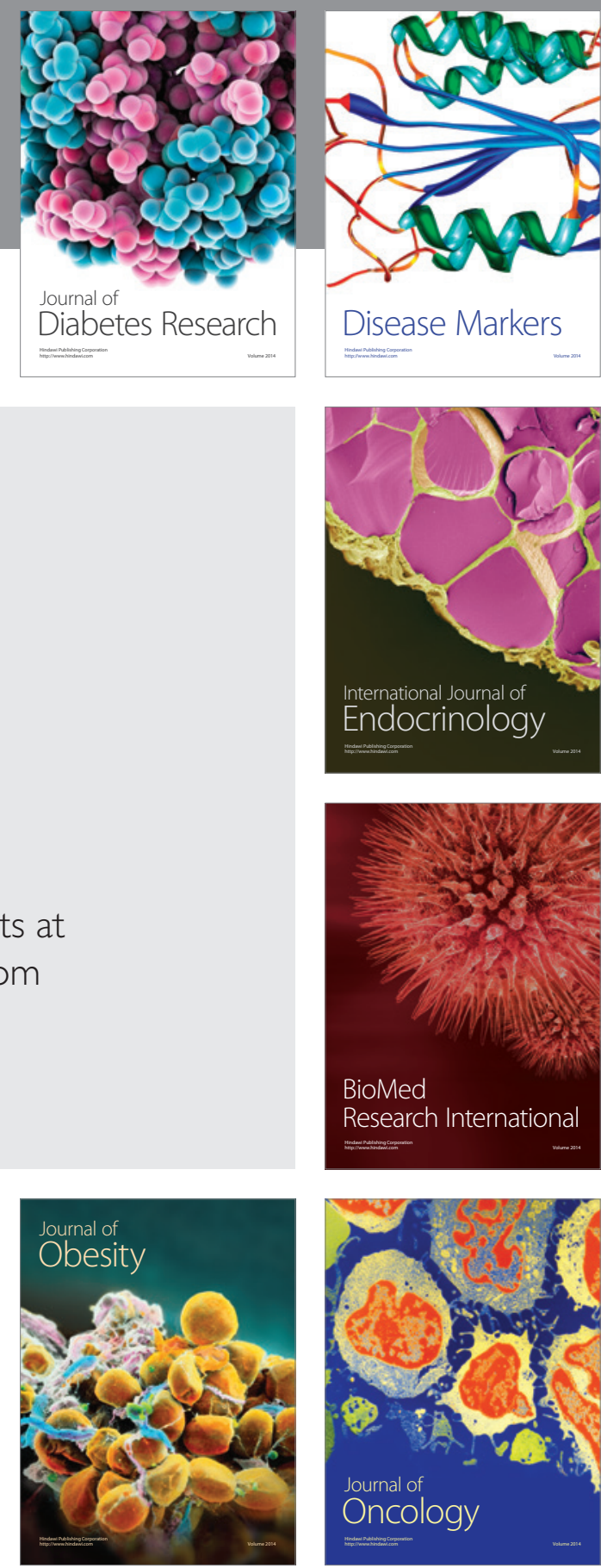

Disease Markers
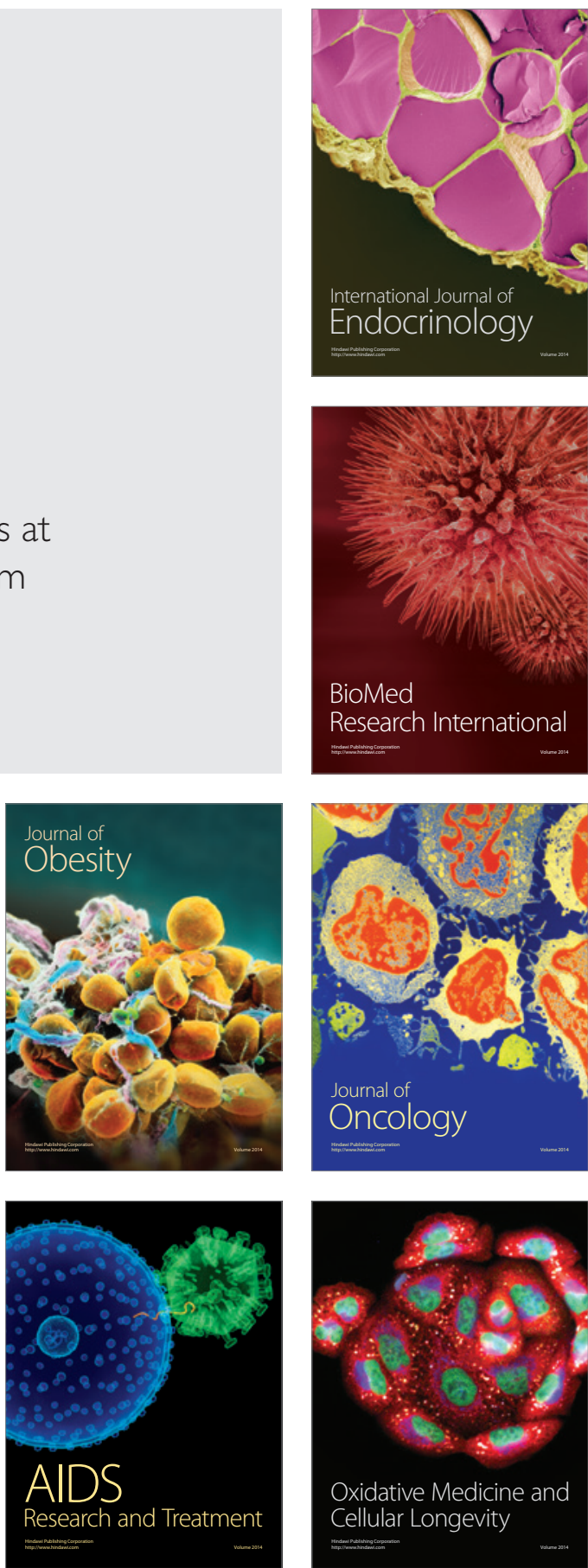